\title{
A NEW MOBILITY SCORE FOR PREDICTING MORTALITY AFTER HIP FRACTURE
}

\author{
MARTYN J. PARKER, CHRISTOPHER R. PALMER
}

From Peterborough District Hospital and the University of Cambridge, England

We assessed 882 patients presenting with a proximal femoral fracture by a new mobility score and by a mental test score, to determine which was of the most value in forecasting mortality at one year. Both scores gave a highly significant prediction, but the mobility score had a greater predictive value and is easier to perform.

J Bone Joint Surg [Br] 1993; 75-B:797-8.

Received 13 July 1992; Accepted after revision 25 March 1993

Many factors have been proposed as predictors of mortality after hip fracture. One of the most reliable is the mental test score (Ions and Stevens 1987; Wood et al 1992). We have compared this with a new mobility score.

\section{PATIENTS AND METHODS}

A total of 882 patients with a proximal femoral fracture were assessed on admission to hospital by a new mobility score (Table I) and a mental test score (Table II). The results were evaluated against the mortality after one year. Statistical analysis, on Egret software (Statistics and Epidemiology Research Corporation, Seattle, WA), was by the chi-squared test for linear trends, and by comparison of logistic regression models (Altman 1990). The estimated specificity, sensitivity and predictive values of the two tests, alone and combined, were also computed.

\section{RESULTS}

Table III gives the number of observed deaths at one year and the percentage of expected deaths predicted from the mobility and mental test scores by logistic regression models. The chi-squared test for linear trend

M. J. Parker, FRCS, Orthopaedic Research Registrar Peterborough District Hospital, Thorpe Road, Peterborough PE36DA, UK.

C. R. Palmer, MS, PhD, Medical Statistician Department of Community Medicine, University of Cambridge, Institute of Public Health, Robinson Way, Cambridge CB2 2SR, UK.

Correspondence should be sent to Mr M. J. Parker.

(C)1993 British Editorial Society of Bone and Joint Surgery $0301-620 X / 93 / 5639 \$ 2.00$ for the mobility score was $133.3(\mathrm{p}<0.001)$ and that for the mental test score was $76.4(p<0.001)$. Logistic regression analysis also indicated that there was a significant independence of the mobility and the mental test scores, with no interaction between the two. The two tests may therefore be combined into a more complex model which gives the percentage chance of survival for mobility and mental test scores:

The percentage chance of survival at 1 year $=100 /$ $[1+$ exponentiation $(1.3-0.3$ (mobility score) 0.07 (mental test score))]. For example, a patient with a mobility score of 7 and a mental test score of 8 will have a predicted chance of survival to one year of:

$100 /[1+$ exponentiation $(1.3-0.3(7)-0.07(8))]=100 / 1$ + exponentiation $-1.36=100 / 1+0.258=80 \%$.

A patient with a mobility score of 3 and a mental score of 1 will have a predicted chance of survival of $42 \%$.

Table I. Assessment of mobility before the fracture. Score is the total, 0 to 9

\begin{tabular}{lllll}
\hline Mobility & $\begin{array}{l}\text { No } \\
\text { difficulty }\end{array}$ & $\begin{array}{l}\text { With } \\
\text { an aid }\end{array}$ & $\begin{array}{l}\text { With help } \\
\text { from another } \\
\text { person }\end{array}$ & $\begin{array}{l}\text { Not } \\
\text { at all }\end{array}$ \\
\hline Able to get about the house & 3 & 2 & 1 & 0 \\
Able to get out of the house & 3 & 2 & 1 & 0 \\
Able to go shopping & 3 & 2 & 1 & 0 \\
\hline
\end{tabular}

Table II. Abbreviated mental test (Qureshi and Hodkinson 1974). The score is the number of questions answered correctly 0 to 10

State age

Give the current time to the nearest hour

Remember an address and repeat it at the end of the test

State the current year

Name the institution to which you have been admitted

Recognise two persons

State date of birth (day and month are sufficient)

Give the year of the start of the Second World War

Name the present monarch or head of state

Count backwards from 20 to 1 
Table III. Number of observed deaths (number, percentage) and expected percentage of deaths at one year predicted by the mobility and mental test scores

\begin{tabular}{|c|c|c|c|c|c|c|c|c|c|}
\hline \multicolumn{5}{|c|}{ Mobility test } & \multicolumn{5}{|c|}{ Mental test } \\
\hline \multirow{2}{*}{$\frac{\text { Score* }}{0}$} & \multirow{2}{*}{$\begin{array}{l}\begin{array}{l}\text { Number of } \\
\text { patients }\end{array} \\
2\end{array}$} & \multicolumn{2}{|c|}{$\begin{array}{l}\text { Oboerved } \\
\text { denths }\end{array}$} & \multirow{2}{*}{$\begin{array}{l}\text { Expected } \\
\text { deaths }\end{array}$} & \multirow{2}{*}{$\frac{\text { Score } †}{0}$} & \multirow{2}{*}{$\begin{array}{l}\begin{array}{l}\text { Number of } \\
\text { patients }\end{array} \\
114\end{array}$} & \multicolumn{2}{|c|}{$\begin{array}{l}\text { Observed } \\
\text { deaths }\end{array}$} & \multirow{2}{*}{$\begin{array}{l}\begin{array}{l}\text { Expected } \\
\text { deaths }\end{array} \\
63\end{array}$} \\
\hline & & 2 & 100 & & & & 66 & 58 & \\
\hline 1 & 25 & 17 & 68 & 68 & 1 & 29 & 14 & 48 & 58 \\
\hline 2 & 102 & 61 & 60 & 60 & 2 & 36 & 22 & 61 & 54 \\
\hline 3 & 196 & 104 & 53 & 52 & 3 & 31 & 19 & 61 & 49 \\
\hline 4 & 121 & 45 & 37 & 43 & 4 & 42 & 18 & 43 & 45 \\
\hline 5 & 65 & 26 & 40 & 35 & 5 & 28 & 16 & 57 & 41 \\
\hline 6 & 60 & 16 & 27 & 27 & 6 & 27 & 12 & 44 & 36 \\
\hline 7 & 46 & 12 & 26 & 21 & 7 & 48 & 25 & 52 & 32 \\
\hline 8 & 5 & 1 & 20 & 16 & 8 & 178 & 45 & 25 & 28 \\
\hline \multirow[t]{2}{*}{9} & 260 & 29 & 11 & 12 & 9 & 263 & 52 & 20 & 25 \\
\hline & & & & & 10 & 86 & 24 & 28 & 22 \\
\hline
\end{tabular}

* chi-squared test for linear trend $133.3 ; \mathrm{df1} ; \mathrm{p}<0.001$

$\dagger$ chi-squared test for linear trend $76.4 ; \mathrm{df} 1 ; \mathrm{p}<0.001$

The estimated sensitivity, specificity and positive and negative predictive values of the tests are given in Table IV, taking the cut-off points as mobility score $<5$ and mental test score $<8$. These points were chosen to divide the total population into groups of equal size. The table also shows the predictive value of using both scores, on the basis of either one being positive or of both being positive.

Briefly expressed, the results show that $73 \%$ of the patients who died had a mobility score of $<5$ and that $71 \%$ of those who were alive after one year had a mental test score of $>7$. Of those with either a mobility score of $>5$, or a mental test score of $>7,84 \%$ survived for at least one year. Of those who had both a mobility score of $<5$ and a mental test score of $<8,59 \%$ died within one year.

\section{DISCUSSION}

The mental test score gives a significant assessment of the likely outcome after a proximal femoral fracture, but the new mobility score has a superior predictive value. This is shown in Table III. The mobility score gives a greater range of predicted mortality, a more consistent pattern, and a better fit for the logistic regression model. Table IV shows that for mortality the mobility score is more sensitive with a higher negative predictive value than the mental test score. For patients satisfying either one of the criteria, the sensitivity and negative predictive value are maximal, while for those who meet both criteria the specificity and positive predictive value of the tests are at their highest.
Table IV. Sensitivity, specificity and predictive values for the mobility and mental test scores

\begin{tabular}{lllll}
\hline & $\begin{array}{l}\text { Mobility } \\
\text { score }<5\end{array}$ & $\begin{array}{l}\text { Meatal test } \\
\text { score }<7\end{array}$ & Either & Both \\
\hline Sensitivity & 0.73 & 0.61 & 0.81 & 0.54 \\
Specificity & 0.62 & 0.71 & 0.54 & 0.79 \\
Negative predictive value & 0.81 & 0.77 & 0.84 & 0.76 \\
Positive predictive value & 0.51 & 0.54 & 0.49 & 0.59 \\
\hline
\end{tabular}

The mobility score is a more functional assessment and also helps by recording the preinjury level of mobility. In addition, alert patients find questions about mobility less disturbing than those about memory and orientation. Many elderly patients with hip fractures are acutely confused by admission to hospital, and this may make the mental test score less reliable.

We recommend the use of the mobility score for the routine assessment of patients with a hip fracture.

No benefits in any form have been received or will be received from a commercial party related directly or indirectly to the subject of this article.

\section{REFERENCES}

Altman DG. Practical statistics for medical research. London: Chapman and Hall, 1990.

Ions GK, Stevens J. Prediction of survival in patients with femoral neck fractures. J Bone Joint Surg [Br] 1987; 69-B:384-7.

Qureshi KN, Hodkinson HM. Evaluation of a ten-question mental test in the institutionalized elderly. Age Ageing 1974; 3:152-7.

Wood DJ, Ions GK, Quinby JM, Gale DW, Stevens J. Factors which influence mortality after subcapital hip fracture. J Bone Joint Surg [Br] 1992; 74-B:199-202. 